\title{
Aplikasi Metode Geolistrik Resistivitas Konfigurasi Wenner Untuk Menentukan Struktur Tanah di Halaman Belakang SCC ITS Surabaya
}

\author{
Andrias Sanggra Wijaya \\ Institut Teknologi Sepuluh Nopember \\ Jl. Arief Rahman Hakim, Surabaya 60111 \\ sanjaya031@gmail.com
}

\begin{abstract}
Abstrak - Telah dilakukan penelitian mengenai aplikasi metode geolistrik resistivitas yang bertujuan untuk menentukan stuktur lapisan tanah di halaman belakang SCC ITS Surabaya. Metode yang digunakan dalam penelitian ini adalah metode geolistrik resistivitas konfigurasi Wenner dengan mengambil data sebanyak tiga lintasan dan masing-masing lintasan berjarak 30 meter. Pengolahan data menggunakan metode optimasi least square non linier dengan inversi $2 D$ yang ada pada software Res2Dinv. Dari hasil analisis tiga lintasan diperoleh bahwa struktur lapisan tanah di halaman belakang SCC ITS terdiri atas air tanah dimana nilai resistivitasnya relatif kecil. Lapisan yang mengandung air tanah tersebut berada pada kedalaman 1,35 sampai 1,99m dengan resisitivitas 0,551-2,73 $\Omega$ m. Selain itu juga terdapat lapisan yang berupa pasir yang bercampur dengan lempung, dan alluvium serta kerikil pada lintasan tiga. Pasir merupakan material batuan yang dapat meloloskan air, namun dengan adanya sisipan lempung maka pada lapisan ini dapat menyimpan air dan mengalirkannya namun dalam jumlah yang terbatas.
\end{abstract}

Kata kunci: Metode Geolistrik Resistivitas, Konfigurasi Wenner.

\begin{abstract}
Has conducted research on the application of geo-electrical resistivity method that aims to determine the structure of the soil layer in the backyard SCC ITS. The method used in this study is the method of geo-electrical resistivity Wenner configuration by taking the data of three tracks and each track is 30 meters. Data processing using non-linear least square optimization with that of the 2D inversion software Res2Dinv. From the analysis of the three trajectories shows that the structure of the soil layer in the backyard SCC ITS consist of ground water where the resistivity values are relatively small. Layer containing the groundwater is at a depth of 1.35 to $1.99 \mathrm{~m}$ with resistivity 0.551 to $2.73 \Omega m$. In addition, there is a layer of sand mixed with clay, and alluvium and gravel on the track three. Sand is a rock material that can pass water, but with the insertion of clay then at this layer can store water and running it but in limited quantities.
\end{abstract}

Key words: Geo-electrical resistivity methods, Resistivity apparent, Wenner configuration method

\section{PENDAHULUAN}

Lapisan tanah suatu daerah tergantung dari kondisi geologi dan iklim. Hal tersebut mengakibatkan kondisi struktur lapisan tanah di halaman belakang SCC ITS beraneka ragam. Untuk mengetahui jenis lapisan batuan yang dilalui oleh air tanah, maka dilakukan dengan mencari nilai resistivitas suatu batuan di bawah permukaan tanah menggunakan metode geolistrik tahanan jenis.

Metode geolistrik merupakan metode yang digunakan untuk mengetahui sifat aliran listrik di dalam bumi dengan cara mendeteksinya di permukaan bumi. Pendeteksian ini meliputi pengukuran potensial, arus dan medan elektromagnetik yang terjadi baik itu oleh injeksi arus maupun secara alamiah. Salah satu metode geolistrik yang sering digunakan dalam pengukuran aliran listrik dan untuk mempelajari keadaan geologi bawah permukaan adalah dengan metode tahanan jenis [7]. Metode geolistrik merupakan metode yang banyak sekali digunakan dan hasilnya cukup baik yaitu untuk memperoleh gambaran mengenai lapisan tanah dibawah permukaan dan kemungkinan terdapatnya air tanah. Pendugaan geolistrik ini didasarkan pada kenyataan bahwa material yang berbeda akan mempunyai tahanan jenis yang berbeda apabila dialiri arus listrik.

Konfigurasi Wenner yang digunakan dalam penelitian ini menggunakan metode mapping. Metode resistivitas mapping merupakan metode resistivitas yang bertujuan mempelajari variasi resistivitas lapisan bawah permukaan secara horisontal. Berdasarkan latar belakang diatas, maka dilakukan penelitian yang bertujuan untuk menentukan struktur lapisan tanah di halaman belakang SCC ITS dengan metode geolistrik konfigurasi Wenner.

\section{METODE PENELITIAN}

A. Metode Geolistrik Resistivitas

Geolistrik adalah salah satu metode dalam geofisika yang mempelajari sifat aliran listrik di dalam bumi. Pendeteksian di atas permukaan meliputi pengukuran medan potensial, arus, dan elektromagnetik yang terjadi baik secara alamiah maupun akibat penginjeksian arus ke dalam bumi. Prinsip kerja metode geolistrik dilakukan dengan cara menginjeksikan arus listrik ke permukaan tanah melalui sepasang elektroda dan mengukur beda potensial dengan sepasang elektroda yang lain. Bila arus 
listrik diinjeksikan ke dalam suatu medium dan diukur beda potensialnya (tegangan), maka nilai hambatan dari medium tersebut dapat diperkirakan. Berdasarkan pada tujuan penelitian metode yang digunakan yaitu metode mapping. Metode resistivitas mapping merupakan metode resistivitas yang bertujuan mempelajari variasi resistivitas lapisan bawah permukaan secara horisontal.

\section{B. Resistivitas Semu}

Metode geolistrik tahanan jenis didasarkan pada anggapan bahwa bumi mempunyai sifat homogen isotropis. Dengan asumsi ini, tahanan jenis yang terukur merupakan tahanan jenis yang sebenarnya dan tidak tergantung pada spasi elektroda. Namun pada kenyataanya bumi tersusun atas lapisan-lapisan dengan resistivitas yang berbeda-beda, sehingga potensial yang terukur merupakan pengaruh dari lapisan-lapisan tersebut. Karenanya, harga resistivitas yang diukur seolah-olah merupakan harga resistivitas untuk satu lapisan saja Resistivitas yang terukur sebenarnya adalah resistivitas semu $\left(\rho_{\mathrm{a}}\right)[6]$.

Besarnya resistivitas semu $\left(\rho_{\mathrm{a}}\right)$ adalah:

$\rho_{a}=\frac{2 \pi}{\left[\left(\frac{1}{r_{1}}-\frac{1}{r_{2}}\right)-\left(\frac{1}{r_{3}}-\frac{1}{r_{4}}\right)\right]} \cdot \frac{\Delta V}{I}$

atau

$$
\rho_{a}=K \frac{\Delta V}{I}
$$

dengan

$$
K=\frac{2 \pi}{\left[\left(\frac{1}{r_{1}}-\frac{1}{r_{2}}\right)-\left(\frac{1}{r_{3}}-\frac{1}{r_{4}}\right)\right]}
$$

Dimana $\mathrm{K}$ adalah faktor geometri yaitu: besaran koreksi letak kedua elektroda potensial terhadap letak elektroda arus [6].

\section{Metode Konfigurasi Wenner}

Metode ini diperkenalkan oleh Wenner (1915). Konfigurasi Wenner merupakan salah satu konfigurasi yang sering digunakan dalam eksplorasi geolistrik dengan susunan jarak spasi sama panjang $\left(r_{1}=r_{4}=a\right.$ dan $\left.r_{2}=r_{3}=2 a\right)$. Jarak antara elektroda arus adalah tiga kali jarak elektroda potensial, jarak potensial dengan titik souding-nya adalah $a / 2$, maka jarak masing elektroda arus dengan titik soundingnya adalah $3 a / 2$. Target kedalaman yang mampu dicapai pada metode ini adalah $a / 2$. Dalam akuisisi data lapangan susunan elektroda arus dan potensial diletakkan simetri dengan titik sounding.
Pada konfigurasi Wenner jarak antara elektroda arus dan elektroda potensial adalah sama. Seperti yang tertera pada gambar 1.

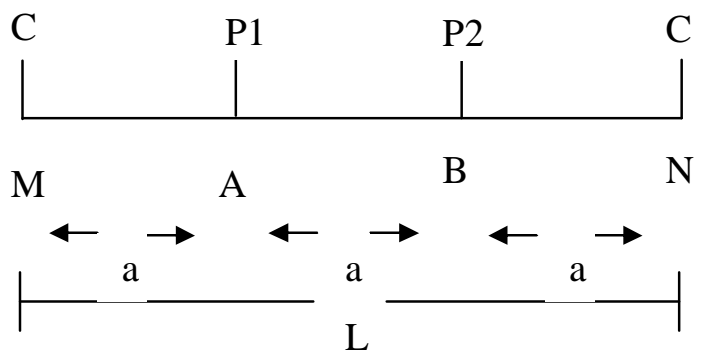

Gambar 1. Elektroda arus dan potensial pada konfigurasi Wenner.

Dari gambar diatas terlihat bahwa jarak $\mathrm{AM}=\mathrm{NB}=\mathrm{a}$ dan jarak $\mathrm{AN}=\mathrm{MB}=2 \mathrm{a}$, dengan menggunakan persamaan (1.3) diperoleh:

$$
\begin{aligned}
& K=\frac{2 \pi}{\left[\left(\frac{1}{a}-\frac{1}{2 a}\right)-\left(\frac{1}{2 a}-\frac{1}{a}\right)\right]} \\
& K=2 \pi a
\end{aligned}
$$

Sehingga faktor geometri untuk konfigurasi Wenner adalah:

$$
K_{w}=2 \pi a \text { dan } \rho_{w}=K_{w} \cdot R
$$

\section{HASIL DAN PEMBAHASAN}

Setelah data pengukuran dan perhitungan didapatkan, kemudian dilakukan inversi 2 dimensi dengan menggunakan metode optimasi least-square non-linier yang ada pada software Res2Dinv. Hasil inversi 2 dimensi ini didapatkan gambar penampang distribusi resistivitas bawah permukaan yang diteliti. Gambar penampang resistivitas pada masing-masing lintasan dapat dilihat pada gambar (2.1,2.2, dan 2.3). 

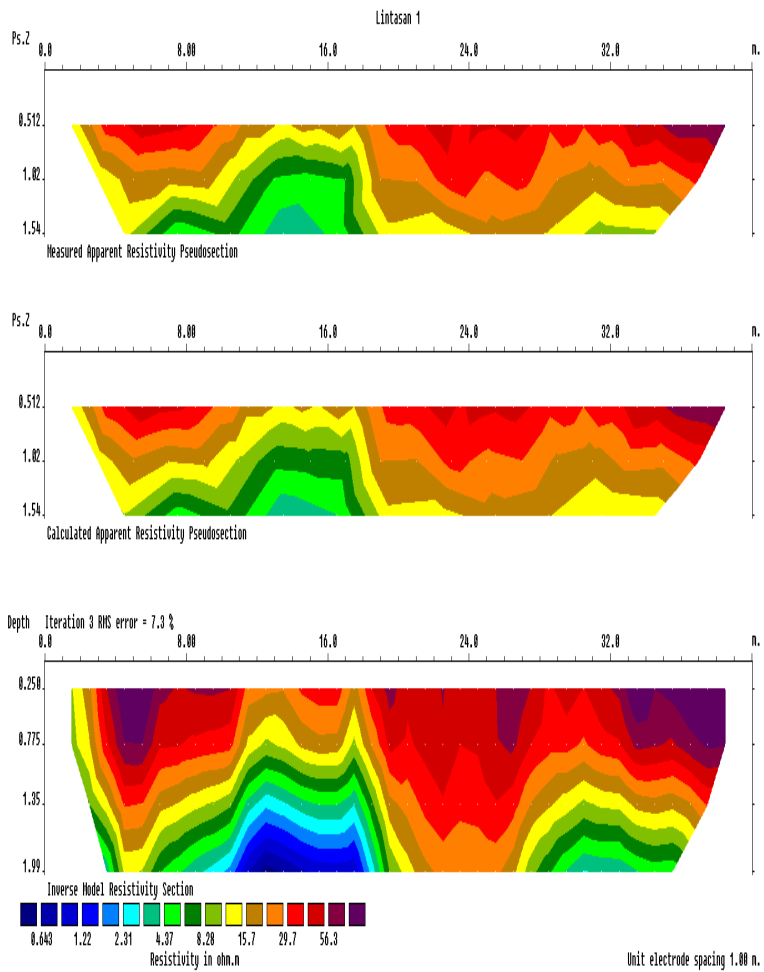

Gambar 2.1 Penampang resistivitas lintasan 1
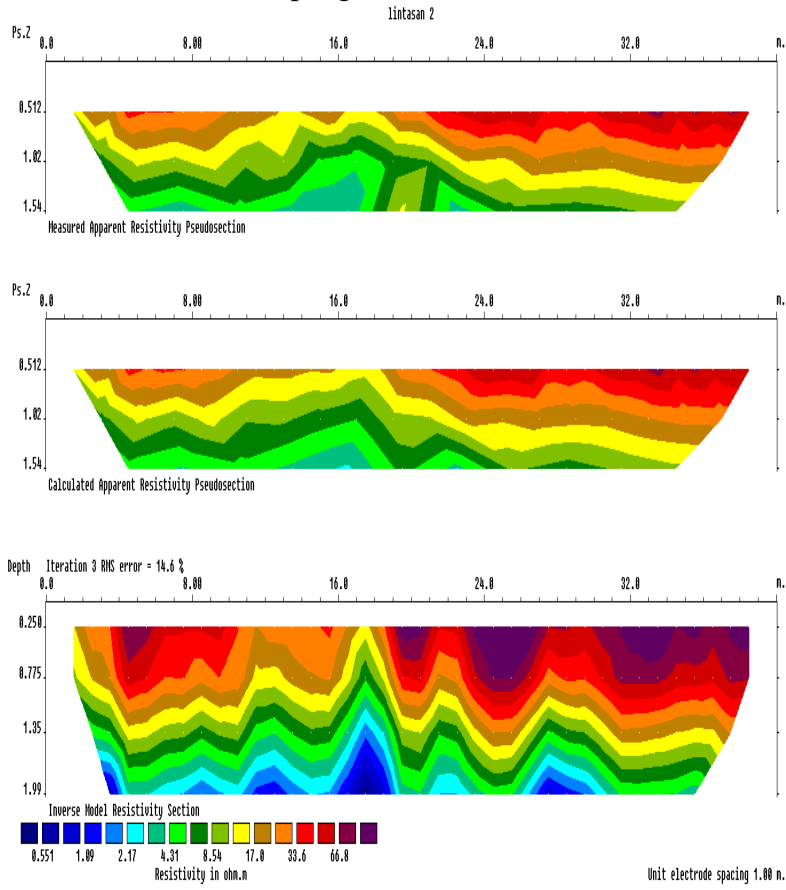

Gambar 2.2 Penampang resistivitas lintasan 2
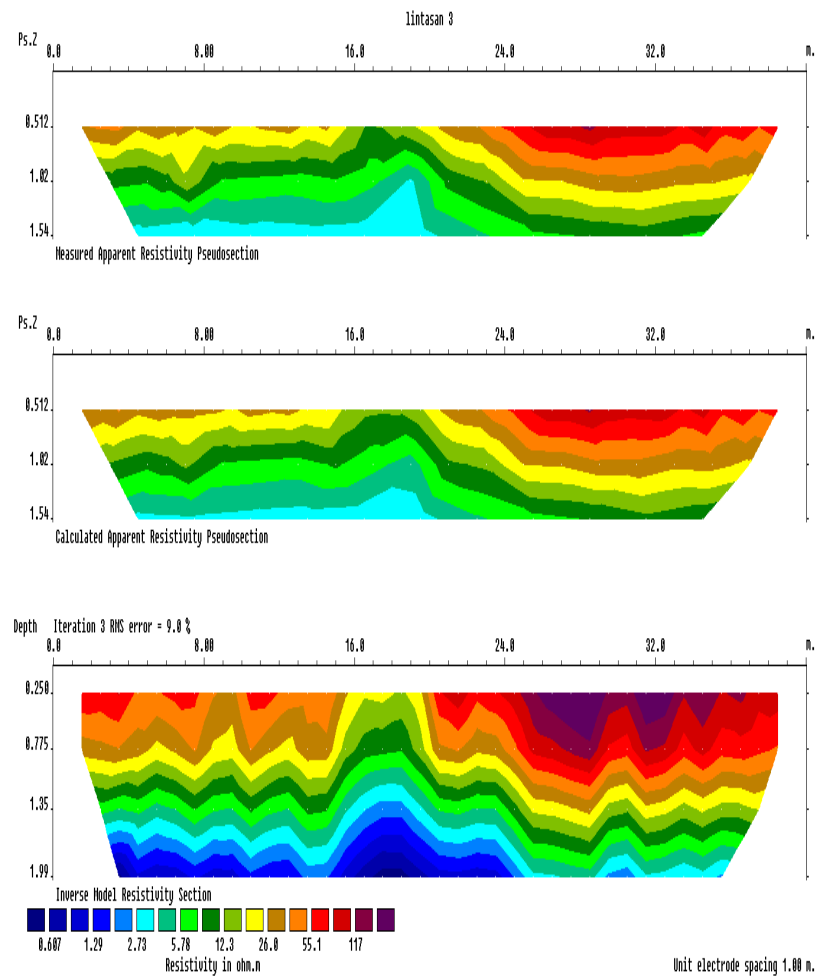

Gambar 2.3 Penampang resistivitas lintasan 3

Dari hasil inversi 2D dengan menggunakan metode least square non linier yang ada pada software Res2Dinv, didapatkan distibusi resistivitas bawah permukaan yang dicitrakan dengan warna yang berbeda (gambar 2.1, 2.2, dan 2.3). Dari gambar penampang resistivitas tersebut dihasilkan tiga bagian gambar yang berbeda pada masing-masing lintasan, yaitu gambar pertama merupakan distribusi resistivitas yang terukur di lapangan, gambar kedua menjelaskan distribusi resistivitas berdasarkan nilai resistivitas semu hasil perhitungan dan gambar ketiga menjelaskan distribusi resistivitas setelah dilakukan inversi yang menunjukkan nilai resistivitas sebenarnya.

Hasil inversi menunjukkan nilai resistivitas sebenarnya yang berbeda dengan resistivitas semu hasil perhitungan. Prosentase kesalahan antara nilai resistivitas semu yang didapatkan melalui pemodelan dengan resistivitas bawah permukaan yang sebenarnya disebut dengan $R M S$ error. RMS error dianggap optimal jika variasi resistivitas bawah permukaan dan sistem pelapisan batuan bawah permukaan sesuai dengan perkiraan kondisi geologi daerah penyelidikan dan tidak harus terkecil [8].

Berikut disajikan tabel nilai resistivitas untuk masingmasing material di bumi. 
Tabel 1 Nilai resistivitas material-material bumi [7]

\begin{tabular}{|l|l|}
\hline \multicolumn{1}{|c|}{ Material } & \multicolumn{1}{c|}{$\begin{array}{c}\text { Resistivitas } \\
\text { (Ohm-Meter) }\end{array}$} \\
\hline Pyrite (Pirit) & $0.01-100$ \\
\hline Quartz (Kwarsa) & $500-800.000$ \\
\hline Calcite (Kalsit) & $1 \times 10^{12}-1 \times 10^{13}$ \\
\hline Rock Salt (Garam Batu) & $30-1 \times 10^{13}$ \\
\hline Granite (Granit) & $200-100.000$ \\
\hline Andesite (Andesit) & $1.7 \times 10^{2}-45 \times 10^{4}$ \\
\hline Basalt (Basal) & $200-100.000$ \\
\hline Limestone (Gamping) & $500-10.000$ \\
\hline Sandstone (Batu Pasir) & $200-8.000$ \\
\hline Shales (Batu Tulis) & $20-2.000$ \\
\hline Sand (Pasir) & $1-1.000$ \\
\hline Clay (Lempung) & $1-100$ \\
\hline Ground Water (Air Tanah) & $0.5-300$ \\
\hline Sea Water (Air Asin) & 0.2 \\
\hline Magnetite (Magnetit) & $0.01-1.000$ \\
\hline Dry Gravel (Kerikil Kering) & $600-10.000$ \\
\hline Alluvium (Aluvium) & $10-800$ \\
\hline Gravel (Kerikil) & $100-600$ \\
\hline
\end{tabular}

Hasil pengukuran pengukuran data geolistrik pada lintasan 1 menunjukkan besarnya nilai resistivitas sebesar 0,643 - 56,3 $\Omega m$. Dengan mencocokkan hasil inversi tersebut dengan tabel 1, maka dapat diketahui jenis lapisan tanah berdasarkan nilai resistivitas semunya. Untuk nilai resistivitas sebesar 0,643-2,31 $\Omega m$ diperkirakan merupakan lapisan dimana terkandung air tanah di dalamnya dimana nilai resistivitasnya relatif kecil. Lapisan yang mengandung air tanah tersebut berada pada kedalaman 1,35-1,99 m yang ditunjukkan dengan warna biru tua. Untuk nilai resitivitas sebesar 4,37-8,28 $\Omega m$ diperikirakan merupakan lapisan yang berupa pasir yang bercampur dengan lempung. Dimana pasir merupakan material batuan yang dapat meloloskan air, namun dengan adanya sisipan lempung maka pada lapisan ini dapat menyimpan air dan mengalirkannya namun dalam jumlah yang terbatas. Untuk nilai resistivitas sebesar 15,7-56,3841 $\Omega m$ diperkirakan merupakan lapisan yang terdiri dari aluvium.

Pada lintasan 2 nilai resistivitasnya berkisar antara 0,551-66,8 $\Omega m$. Berdasarkan tabel 1, diketahui jenis lapisan tanah berdasarkan nilai resistivitas semunya. Untuk nilai resistivitas sebesar 0,551-2,17 $\Omega m$ diperkirakan merupakan lapisan dimana terkandung air tanah yang berada pada kedalaman 1,35-1,99 m dengan ditunjukkan dengan warna biru tua pada gambar 2.2. Untuk nilai resitivitas sebesar 4,31-8,54 $\Omega m$ diperikiran merupakan lapisan yang berupa pasir yang bercampur dengan lempung. Sedangkan untuk nilai resistivitas sebesar 17,8-66,8 $\Omega m$ diperkirakan merupakan lapisan yang terdiri dari aluvium.

Sedangkan pada lintasan 3 besarnya nilai resistivitas sebesar 0,607-117 $\Omega m$. Berdasarkan tabel 1, diketahui jenis lapisan tanah berdasarkan nilai resistivitas semunya. Untuk nilai resistivitas sebesar 0,607-5,78 $\Omega m$ diperkirakan merupakan lapisan dimana terkandung air tanah yang berada pada kedalaman 1,35-1,99 m dengan ditunjukkan dengan warna biru pada gambar 2.3. Untuk nilai resitivitas sebesar 12,3-117 $\Omega m$ diperikiran merupakan lapisan yang berupa pasir yang bercampur dengan lempung dan kerikil yang resistivitasnya kerikil berkisar antara 100-600 $\Omega m$ berdasarkan tabel 1 .

Hal ini juga sejalan dengan penelitian sebelumnya [1] yang menyatakan bahwa struktur tanah di halaman belakang SCC ITS tersusun atas campuran tanah alluvial, air tanah, pasir, dan kerikil.

\section{KESIMPULAN}

Penelitian ini memberikan gambaran mengenai struktur lapisan tanah yang berada di halaman belakang SCC ITS Surabaya. Dari hasil analisis diperoleh bahwa struktur lapisan tanah di halaman belakang SCC ITS terdiri atas air tanah dimana nilai resistivitasnya relatif kecil. Lapisan yang mengandung air tanah tersebut berada pada kedalaman 1,35 sampai 1,99m dengan resisitivitas 0,551$2,73 \Omega \mathrm{m}$. Selain itu juga terdapat lapisan yang berupa pasir yang bercampur dengan lempung, dan aluvium serta terdapat kerikil pada lintasan tiga. Pasir merupakan material batuan yang dapat meloloskan air, namun dengan adanya sisipan lempung maka pada lapisan ini dapat menyimpan air dan mengalirkannya namun dalam jumlah yang terbatas.

\section{PUSTAKA}

[1] Arifin, syaiful, dkk. 2012. Identifikasi Struktur Bawah Permukaan Tanah dengan Metode VLF. Jurusan Fisika, FMIPA, ITS. Surabaya.

[2] Hendrajaya, L. \& Arif, I. 1990. Geolistrik Tahanan Jenis. Monografi: Metoda Eksplorasi. Laboratorium Fisika Bumi. ITB,Bandung.

[3] Khalil, M. H., (2006), Geo-electrical resistivity sounding for delineating salt water intrusion in the Abu Zenima area, West Sinai, Egypt, Journal Geophysics and Engineering, 3: 243-251.

[4] Lashkaripour, G. R., (2007), An investivigation of groundwater condition by geoelctrical resistivity method: A case study in Korin Aquifer, Southeast Iran, Journal of Spatial Hydrology, 7(2).

[5] Mohammed, L. N., Aboh, H. O. \& Emenike, E. A., (2007), A regional geo-electrical investivigation for groundwater exploration in Minna Area, North West Nigeria, Science World Journal, 2(4): 15-19. 
[6] Reynolds, J. M. 1997. An Introduction to Aplied and Environmental Geophysicsi. John Wiley and Sons Ltd. Baffins, Chichester, West Susex PO19 IUD. England.

[7] Telford, W. M; Geldart, L. P; Sherif, R.E dan Keys, D. D. 1976. Applied Geophysics First Edition. Cambridge University Press. Cambridge.New York.

[8] Wahyono C.S; W. Utama; N. Priyantari. 2003. Penentuan Bidang Gelincir pada Daerah Rawan Longsor dengan Menggunakan Metode Geolistrik 2-D di Desa Lumbang Rejo, Prigen, Pasuruan, Program Pasca Sarjana Fisika, Bidang Keahlian Geofisika. Jurusan Fisika FMIPA ITS. Surabaya. 